\title{
Representações de gênero em Vira-Vira, Violeta
}

\author{
Gender Representations in Vira-Vira, Violeta \\ Rozeane Porto Diniz' (iD) 0000-0002-6834-071X \\ Geam Karlo-Gomes² (iD 0000-0001-9569-1497 \\ 'Universidade Federal Rural de Pernambuco, Programa de Pós-Graduação em História. \\ Recife, PE, Brasil.52171-900 - secretaria.pgh@ufrpe.br \\ ${ }^{2}$ Universidade de Pernambuco, Programa de Pós-Graduação em Formação de \\ Professores e Práticas Interdisciplinares, Petrolina, PE, Brasil. 56360-650 - \\ petrolina.letras.coord@upe.br
}

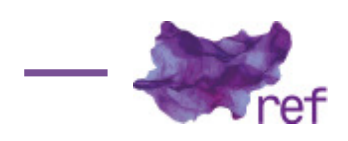

LACERDA, Socorro.

Vira-vira, Violeta.

Petrolina, PE: Edição da Autora, 2017.

Socorro Lacerda, professora, feminista e filha do Rio São Francisco - autodescrição da autora -, lançou, em 2017, o seu segundo livro: Vira-Vira, Violeta. Trata-se de uma obra de literatura infantojuvenil com discussões sobre diversas representações de gênero, apresentando, de forma estratégica, personagens que estão no cerne dessa problematização. É surpreendente o quanto o livro é acessível, podendo ser lido por pessoas de qualquer idade, pois, mesmo numa linguagem coerente com o público infantojuvenil, traz configurações de personagens históricas muito significativas para o contexto de luta por igualdade de gênero.

O livro de Socorro aborda as relações de gênero a partir da protagonização de uma luta das mulheres, representadas na narrativa pelas personagens nomeadas como Violetas, em prol da igualdade de direitos em relação aos homens, configurados no livro como Cravos. Violetas e Cravos são nomes e personagens simbólicos usados pela autora para protagonizar a luta e a resistência entre homens e mulheres.

A narrativa é mesmo muito simbólica. O dicionário de símbolos de Jean Chevalier e Alain Gheerbrant (2017) aponta o significado da cor violeta como temperança, "de lucidez, de ação refletida, de equilíbrio entre terra e o céu, os sentidos e o espírito, a paixão e a inteligência, o amor e a sabedoria" (Jean CHEVALIER; Alain GHEERBRANT, 2017, p. 960). Essas características reforçam a razão, a firmeza e coragem da personagem Violeta Borboleta e todas as Violetas da região em prol do movimento "violetas unidas jamais serão vencidas" (Socorro LACERDA, 2017, p. 35). Já os cravos brancos não apresentam característica de pureza e inocência; pelo contrário, a cidade dos cravos brancos é representada pelo prefeito carrancudo, Cravo Olavo.

Numa relação íntima com a natureza, a personificação das flores instaura uma dimensão do ecofeminismo logo nas primeiras páginas da obra: "Violeta Loreta puxava os raios de sol para raiar o dia", enquanto "Violeta Dandara capoeirava para o vento" e "Violeta Julieta despertava o galo para que a manhã começasse bem linda com seu canto", já "Violeta Risoleta encomendava 
chuva às nuvens" e Violeta Chiquinha "esperava os pássaros [...] com o som do seu piano de teclado de pedrinhas" (LACERDA, 2017, p. 17-18).

Ora, o ecofeminismo é uma vertente da ecocrítica que teve início com a atuação de Françoise D'Eaubonne nos anos de 1970, na França, e se popularizou a partir da década de 1980. E no tocante a esse contexto, a obra de Socorro Lacerda vem nos ensinar que, assim como a Terra e o Feminino são duas realidades inter-relacionadas, pois é da Terra que nascem os seres e é ela que, tal como Ésquilo registra em Coéforas, "os nutre, e deles recebe, depois, o germe fecundo" (ÉSQUILO, 2004 apud Mircea ELIADE, 2010, p. 117), a luta pelos direitos das mulheres não pode ser separada da luta pela regeneração do ecossistema. Com efeito, a autora vem nos alertar que a visão ecológica da realidade possui relação íntima com uma ecologia humana desprovida de qualquer forma de dualismo. Dessa forma, não há espaço para contrastes: matriarcado, patriarcado, dominante, dominado... Pois a obra nos guia a mensagem de que a cidade é das Violetas e dos Cravos. Em outras palavras, a defesa pelos direitos iguais entre homens e mulheres é a principal temática dessa trama.

Nesse sentido, as relações de gênero se enredam no livro a partir do momento em que as Violetas decidem lutar em prol de liberdade e igualdade em relação aos Cravos. As Violetas eram proibidas de exercer inúmeras atividades: andar de bicicleta, votar e até mesmo falar nas reuniões realizadas com os Cravos. Os Cravos, por sua vez, naturalizavam a situação e se recusavam a escutar as reclamações das Violetas por temerem perder sua autoridade, pregando o "deixacomoestá" (LACERDA, 2017, p. 10). Ou seja, não aceitavam qualquer transformação que pudesse afetar seu lugar de poder. O discurso dos Cravos configura aquilo que Sócrates Nolasco (2001 , p. 78) atribuí ao "homem de verdade", que se comporta de forma agressiva, determinada e sempre tentando intimidar pelo domínio do espaço de fala e de ação.

Todavia, esse discurso não se sustenta, pois as Violetas desnaturalizam os papéis de gênero que lhes são atribuídos. Isso nos lembra as diversas discussões sobre a construção de papéis de gênero de forma naturalizada, ao perceber, assim como Monique Wittig (2009, p. 238) ao retomar Simone Beauvoir, que "ninguém nasce mulher".

Nesse sentido, a autora traz a reação das Violetas à afirmação dos Cravos, representados pelo prefeito, Cravo Olavo, de que nada deveria mudar. Porém, a reação das Violetas é engajada, trazendo uma bandeira de luta chamada "\#Violetastambémpodem" (LACERDA, 2017, p. 15). Com isso, o livro traz à tona o engajamento de mulheres em prol da resistência e desconstrução de papéis que atribuía às Violetas: o espaço de recatadas e do lar.

Poderíamos citar inúmeras historiadoras, literatas, entre outras que problematizaram essa atribuição de submissão das mulheres, mas lembramos de Mary del Priore (2006, p. 218), quando afirma que social e historicamente: "a mulher tinha de ser naturalmente frágil, [...], submissa etc. As que revelassem atributos opostos seriam consideradas seres antinaturais". Nesse sentido, ViraVira, Violeta suscita discussões teóricas de gênero que podem ser problematizadas nos mais diversos espaços possibilitando que a obra seja discutida com crianças e adolescentes. Também pode ser lida e debatida pelo público adulto, desde que o objetivo seja discutir as relações de gênero, desconstruindo estereótipos e demonstrando a necessária igualdade de direitos entre os gêneros.

Assim, o livro aciona diversos/as autores/as, teorias e personagens engajados/as nas discussões pela igualdade de gênero e, de forma enriquecedora, exemplifica, por meio de personagens, histórias de diversas lutas e símbolos de resistência. Por exemplo, a personagem que desejava ser astronauta se aproxima das restrições impostas às mulheres em países do Oriente Médio; Violeta Chiquinha pode ser uma genuína representação da primeira maestrina brasileira, entre outras personagens históricas. Ou seja, a composição das personagens não surge ao acaso, mas histórica e estrategicamente foram selecionadas para compor uma narrativa ancorada em fatos da realidade.

Vira-Vira, Violeta tem importância significativa no campo da literatura infantojuvenil. Pode contribuir para discutir relações de gênero com crianças e adultos, mas se destaca, sobretudo, por acender a discussão de (des)igualdade entre meninos e meninas, tendo em vista que são poucas as obras que possibilitam, por sua composição narrativa, uma discussão fluída e compreensível a qualquer público leitor.

Além de todas as estratégias na composição da narrativa, vale a pena observar que, tanto a campanha dos Cravos quanto a das Violetas estão ancorados em movimentos e/ou palavras de ordem de homens e mulheres. O primeiro, em torno da manutenção da ordem do pai; o segundo, das mulheres, na reafirmação de sua liberdade e da reivindicação de seus direitos. Isso está exemplificado no "deixacomoestá" (LACERDA, 2017, p. 10) e "\#Violetastambémpodem" (LACERDA, 2017 , p. 15), retomando estratégias de lutas, especialmente das mulheres que acabam elegendo alguma frase e/ou palavra de ordem que se torna bandeira de luta e se populariza nos meios de comunicação, geralmente protagonizados por grupos de engajamento político. Além disso, lutar por voto, pelo direito à fala, por espaço no mercado de trabalho e nas artes, entre outros, configuram, de forma pontual, as principais lutas e reivindicações feministas ao longo da história. 
É interessante também destacar o cenário em aquarela elaborado pela ilustradora Karla Gonçalves e construído para materializar uma narrativa na qual, talvez, Violetas "borram" as fronteiras de gênero, destoando limites e divisões, registrando a marca do feminino como símbolo de uma participação social ativa.

Por mais que o cenário e a narrativa produzam encantamento, o livro surpreende quando percebemos que as Violetas ganham vida. Talvez o livro produza estranhamento quando os Cravos, com pouca resistência, acabam cedendo à luta das Violetas, já que, historicamente, os homens resistiram e ainda relutam em alguns espaços em reconhecer e/ou aceitar a igualdade de direitos entre homens e mulheres. Mas talvez essa seja a grande metáfora da obra de Socorro Lacerda: é preciso pincelar os cravos de um "vermelho-beterraba-cozida" (LACERDA, 2017, p. 30), pois no tocante à discussão de gênero, não cabe dualismo, e sim, diálogo, reciprocidade, altruísmo.

\section{Referências}

CHEVALIER, Jean; GHEERBRANT, Alain. Dicionário de símbolos. Trad. de Vera da Costa e Silva. Rio de Janeiro: José Olympio, 2017.

ELIADE, Mircea. O sagrado e o profano: a essência das religiões. Trad. de Rogério Fernandes. São Paulo: Editora WMF Martins Fontes, 2010.

LACERDA, Socorro. Vira-vira, Violeta. Petrolina, PE: Edição da Autora, 2017.

NOLASCO, Sócrates. De Tarzan a Homer Simpson: banalização e violência masculina em sociedades contemporâneas ocidentais. Rio de Janeiro, Rocco, 2001.

PRIORE, Mary Del. História do amor no Brasil. São Paulo: Contexto, 2006.

WITTIG, Monique. "Ninguém nasce mulher". In: CASTILHOS, Clarisse; PESSAH, Marian. (Orgs.) Em rebeldia da bloga ao livro. Porto Alegre: Coleção Libertaria, 2009. p. 237-248.

Rozeane Porto Diniz (rozeane_porto@yahoo.com.br) é pós-doutoranda em História pela UFRPE. Doutora e Mestra em Literatura e Interculturalidade pela UEPB. Mestra em História pela UFPB. Participa do Núcleo de Investigações e Intervenções em Tecnologias Sociais/NINETS, do Grupo de Pesquisa: Estudos de Gênero e de sexualidades, ambos da Universidade Estadual da Paraíba e do Laboratório de Estudos e Intervenções em Patrimônio Cultural e Memória Social/LEPAM da UFRPE.

Geam Karlo-Gomes (geam.k@upe.br) é doutor e mestre pelo Programa de Pós-Graduação em Literatura e Interculturalidade (UEPB). Professor do Programa de Pós-Graduação em Formação de Professores e Práticas Interdisciplinares - PPGFPPI - Universidade de Pernambuco. Líder do ITESI - Grupo de Pesquisa Itinerários Interdisciplinares em Estudos sobre o Imaginário. Entre outros trabalhos, é autor de O Diário de leituras na escola e na universidade: estudos do gênero e práxis pedagógica, pela Mercado de Letras.

\section{COMO CITAR ESSE ARTIGO DE ACORDO COM AS NORMAS DA REVISTA}

DINIZ, Rozeane Porto; KARLO-GOMES, Geam. "Representações de gênero em Vira-Vira, Violeta". Revista Estudos Feministas, Florianópolis, v. 28, n. 2, e67748, 2020.

\section{CONTRIBUIÇÃO DE AUTORIA}

Rozeane Porto Diniz - redação e revisão do texto quanto representação e historicidade da obra para a discussão sobre as relações de gênero, configurando a resistência das mulheres frente à naturalização dos papéis sociais e a desconstrução dos estereótipos.

Geam Karlo-Gomes - redação e revisão do texto quanto à hermenêutica dos aspectos imagéticos e simbólicos da obra resenhada e análise do ecofeminismo.

\section{FINANCIAMENTO}

Não se aplica.

\section{CONSENTIMENTO DE USO DE IMAGEM}

Não se aplica. 


\section{APROVAÇÃO DE COMITÊ DE ÉTICA EM PESQUISA}

Não se aplica.

\section{CONFLITO DE INTERESSES}

Não se aplica.

LICENÇA DE USO

Este artigo está licenciado sob a Licença Creative Commons CC-BY International. Com essa licença você pode compartilhar, adaptar, criar para qualquer fim, desde que atribua a autoria da obra.

\section{HISTÓRICO}

Recebido em 24/09/2019

Aprovado em 08/12/2019 